\title{
Antibacterial activity of ginger extracts on bacteria isolated from digestive tract infection patients attended Muhoza Health Center
}

\author{
Callixte Yadufashije ${ }^{1}$, Adolyne Niyonkuru², Emanuel Munyeshyaka², Sibomana Madjidi², \\ Joseph Mucumbitsi ${ }^{3}$ \\ ${ }^{1}$ Senior Lecturer, Department of Biomedical Laboratory Sciences and Director of Research and Consultancy at INES- \\ Ruhengeri-Institute of Applied Sciences, ${ }^{2}$ Laboratory Technician in Clinical Microbiology Laboratory at INES-Ruhengeri- \\ Institute of Applied Sciences, ${ }^{3}$ Lecturer and Coordinator of Research in Department of Biomedical Laboratory Sciences \\ at INES-Ruhengeri-Institute of Applied Sciences
}

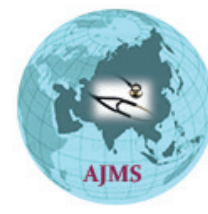

A B S TR A C T

Background: Ginger (Zingiber officinale) has been used for long time due to its potential antimicrobial activity against diversity of microbial pathogens. Aims and Objectives: The study was carried out to investigate the bacteria pathogens found in digestive tract infections and assess antimicrobial activities of ginger extract to identified bacteria. Materials and Methods: Bacteriological studies were carried out on stool samples from 30 patients attending Muhoza health center. Different types of bacteria were isolated from stool samples of digestive tract infection patients by using various methods such culture, biochemical test and antimicrobial activity of ginger extracts was analyzed at INES-Ruhengeri in clinical microbiology laboratory. Results: Study findings showed isolated bacteria and antibacterial activity of Ginger. Isolated bacteria and their percentages including Escherichia coli $(46.6 \%)$ which is the predominant isolated bacteria, Salmonella species (33.33\%), Enterobacter spp (10.0\%), Shigella spp (6.6\%) and Citrobacter $(3.33 \%)$ which is the least isolated bacteria. Antibacterial activity of ginger was seen on isolated bacteria, as ethanol and methanol were used for ginger oil extraction, the antibacterial activity of ginger extracts using ethanol was seen on isolated bacteria such us Citrobacter spp with $14 \mathrm{~mm}$ of inhibition zone, Shigella spp with $12 \mathrm{~mm}$, Salmonella with $11.1 \mathrm{~mm}$, E. coli with $9.5 \mathrm{~mm}$ and Enterobacter spp which was seen to be resistant to ginger extract using ethanol with $0.66 \mathrm{~mm}$ of inhibition zone. For methanol extracts antibacterial activity was seen as follows: Citrobacter spp at $12 \mathrm{~mm}$, Shigella spp at $11 \mathrm{~mm}$, E. coli at $8 \mathrm{~mm}$, salmonella spp at 6.1 $\mathrm{mm}$, and Enterobacter spp with $5 \mathrm{~mm}$. Enterobacter spp was seen to be the most resistant bacteria in both extracts. Conclusion: Ginger has shown to have an antibacterial activity on bacteria isolated from digestive tract infected patients. It can be used as a medicine to treat these infections. Number of researches should be done to be sure on this reality of antibacterial activity of ginger.

Key words: Ginger; Extracts; Inhibition zone; Antibacterial

\section{INTRODUCTION}

Both misuse and overuse of antibiotics have been a leading cause of the evolution of antibiotics resistance mechanism amongst pathogenic bacteria. Bacteria have developed different mechanism to inhibit the effect antibiotics. ${ }^{1}$ The resistance to antimicrobial agents can be natural, acquired, genetic, phenotypic or biological. ${ }^{2}$ Furthermore, resistance may be developed due to spontaneous mutation in genes, acquisition of plasmid or transposon, the physiological change in the state of bacterial cell or decreasing of the permeability of cell. Bacteria develop resistance in various ways such as enzymatic drug inactivation, drug target alteration and drug permeability reduction. ${ }^{3}$ Thus bacteria 
continue to grow in the presence of a given antimicrobial agent.

Recently, the list of various non-antibiotics approaches was done based on their antimicrobial activities in treatment and prevention of infectious diseases such as probiotic, bacteriophage and phytomedicines. ${ }^{4}$ Moreover, plants are not in introductory phase in the history of medicine, they have been used as medicines for long and are known to be the good cure of various infectious and non-infectious diseases worldwide. ${ }^{5}$ According to the report of World Health Organization, near by 80 percent of the world population depend primarily on traditional medicine which influence the high involvement of the use of both plants extracts and their active substances. ${ }^{3}$ Ginger extracts is one of those medicinal plants that played a huge role in treatment of different diseases. Ginger has strong properties that kill or inhibit the growth of pathogenic bacteria; and previously it was seen that active components of ginger inhibit multiplication of

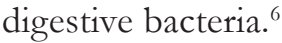

Ginger (Zingiber officinale), because of its antimicrobial ability against different microbial pathogens, it has been used as naturopathy. ${ }^{7}$ Ginger has been against number of pathogenic microorganisms in its natural state, without transforming it which is a proof of using it as a strong medicine in treatment of infectious diseases. ${ }^{1}$ Ginger belongs to Zingiberaceae family, the Zingiberaceous plants are naturally with strong aromatic and medicinal properties and are characterized by their tuberous or non-tuberous rhizomes. Ginger is available and accessible at low cost for everyone to use it, it is universally acceptable and well tolerated by the most people. ${ }^{3}$

Ginger has both gingerols and shogaols that are rich in antimicrobial effects helps in resolving stomach infection and other health outcomes. It has strong antimicrobial properties and active constituents of ginger inhibit the replication of colon bacteria. It inhibits the growth of E. coli, Staph, spp., and more. ${ }^{2}$ Okiki et al mentioned that the antimicrobial activity of ginger may be due to phenolic compounds considered. ${ }^{4}$ Traditionally, Ginger was used in treatment of intestinal infections, especially those related to digestive health outcomes. ${ }^{8}$ It is against this background that this study is going to assess antimicrobial activity of ginger against bacteria most commonly found in digestive tract.

Antibiotic resistance is one of the biggest epidemic to global health especially in low and middle income world. Drugs resistance is a leading cause of higher costs, prolonged hospital stays and increase mortality. ${ }^{3}$ Number of studies have been carried out on plant medicines aimed to show the ability of plants to fight against bacterial infections. Even though number ofstudies have been done, their findings and recommendations were not taking into consideration by policy makers to facilitate easy accessibility of health care in low and middle income countries. Therefore, this study was carried out in order to remind people that plants such ginger are still suitable solutions for antibiotics resistance.

\section{MATERIALS AND METHODS}

\section{Study area}

This study was conducted at Muhoza health center located in Muhoza sector, Musanze district, Northern Province of Rwanda, road (Musanze-Rubavu) and near national police college. The research work was located in the field of clinical microbiology.

\section{Study design}

This study was cross sectional study and was conducted from October to December 2019. Stool samples were taken from the patients suffering from digestive tract infections attending Muhoza health center.

\section{Study population and sample size}

The target population of this study was patients suffering from digestive tract infection attending Muhoza health center. 30 Stool samples which was liquid (diarrheic) or soft were collected adequately for cultured and antibiogram test for the identified bacteria to be analyzed at Ines Ruhengeri clinical microbiology laboratory.

\section{Collection of stool sample}

Stool samples were collected using clear instructions given for proper specimen collection. Feces should be collected in a clean, dry container with a tight lid and should not be contaminated with urine, barium, or toilet paper and water. Specimen containers or collection devices should be labeled with the patient identifiers, such as name or record number and date of birth this was done carefully to avoid biased laboratory results.

\section{LABORATORY ANALYSIS}

\section{Macroscopic examination}

Macroscopic examination was performed by observing stool sample with eyes. The identified abnormalities of stool samples were based on color, consistency, amount, shape, odor, and the presence of mucus and blood. Normally, the stool appears brown, soft, and well-formed in consistency. A noticeable, if there is any change, it indicates infections. Thus, before microscopic examination, all stool clinical manifestation was considered. 


\section{Preparation of culture media}

MacConkey, Salmonella Shigella and blood Agar were prepared by dissolving some grams of given amount of dehydrated culture media to 1 liter of distilled water. Heated with repeated stirring and boiled for 1 minute to dissolve completely. Then the prepared solution was autoclaved at $121^{\circ} \mathrm{C}$ for 15 minutes except SSA autoclave only distilled water, then cools down and distributed in the Petri dish and waited for culture medium to be solidified. But blood agar cools to $45^{\circ}-50^{\circ} \mathrm{C}$, aseptically add $50.0 \mathrm{~mL}$ of blood. Mix thoroughly and pour into sterile Petri dishes.

\section{Inoculation and incubation}

Pour plate method was used for inoculation of bacteria samples into prepared Petri dishes of MacConkey, Salmonella Shigella and blood agar. The plates were aerobically incubated at $35-37^{\circ} \mathrm{C}$ for $18-24 \mathrm{hrs}$. Then examine the grown colonies

\section{BIOCHEMICAL TEST}

Triple sugar iron test

An inoculating straight loop was sterilized in the blue flame of the Bunsen burner and then allowed to cool. A colony of the suspected organism from culture media was picked, stabbed into the medium up to the butt of the TSI tube and then was streaked back and forth along the surface of the slant. Again, the neck of the TSI was flamed, capped and placed in the incubator for $18-24$ hours at a temperature of $37^{\circ} \mathrm{C}$.

\section{Sugar fermentation}

The test was tested in KIA, media having sugar to identify Enterobacteriaceae. Acid production changed the color of medium, from pink to yellow. Glucose results were on bottom, lactose results found on the slope H2S results for sulfur reduction in Durham's tube and results for gas production.

\section{Indole production}

The test was performed in sulfur indole motility media (SIM) to identify Enterobacteriaceae. Some of gram negative bacilli bacteria use tryptophan found in the media to produce indole. After 24 Hours of culturing, $0.5 \mathrm{ml}$ of Kovac's was added in the medium in order to observe the change in color.

\section{Motility test}

The test was used to identify that the present bacteria hand flagella helped them to swimming away from a stab mark in SIM media. The result was recorded after checking the turbidity of medium.

\section{Citrate utilization}

Same gram-negative bacilli use carbon as sole source of energy. In Simmon's citrate after overnight incubation, color of medium changed from green to blue if citrate is used up by the organism.

\section{Urease test}

The test was done in urease broth media and incubated at $37^{\circ} \mathrm{C}$. Urease producing organism produced pink color. The hydrolysis of urea forms the weak base, ammonia, as one of its products. This weak base raiser the $\mathrm{pH}$ of the media above 8.4 and the $\mathrm{pH}$ indicator, phenol red, from yellow to pink.

Ginger extracts preparation: Oil extraction from Ginger Fresh ginger rhizomes were washed, peeled, sliced, shadow dried and dried in hot oven for $70^{\circ} \mathrm{C}$. Dried ginger was grounded to fine powder using electric blender 90 grams of ginger powder was soaked in $450 \mathrm{ml}$ of 99 methanol and $450 \mathrm{ml}$ of 95 ethanol separately. The flasks were incubated at room temperature for 72 hours. The crude extracts filtered with whatman filter paper. The extracts were concentrated using a rotary evaporator at $78^{\circ} \mathrm{C}$. Essentials oil extracts are kept in sterile container at $4^{\circ} \mathrm{C}$ until to be used for checking antimicrobial activity.

\section{Mueller Hinton Agar preparation}

Mueller Hinton agar (MHA) is recommended for antimicrobial disk diffusion susceptibility testing of common, rapidly growing bacteria by the Kirby-Bauer method as standardized by the Clinical Laboratory Standards Institute (CLSI). Suspend 22 grams in $600 \mathrm{ml}$ purified/ distilled water. Heat to boiling to dissolve the medium completely. Sterilize by autoclaving at $15 \mathrm{lbs}$ pressure $\left(121^{\circ} \mathrm{C}\right)$ for 15 minutes. Cool to $45-50^{\circ} \mathrm{C}$. Mix well and pour into sterile Petri plates.

\section{Antibacterial activity of Ginger extracted Oil}

Blanck discs (6mm diameter) were sterilized in a dry heat sterilizer and kept in the refrigerator for further use. A lawn of each bacterial isolate was prepared on MHA plates using a sterile cotton swab from the inoculum showing growth. MHA plates were dried for 15 minutes in the laminar air flow cabinet. Three filter paper discs were placed one on top of other on dried MHA plates and ginger oil extracts $(20 \mu \mathrm{l})$ were added on each disc separately. Ginger oil extracted by two different alcohols (ethanol and methanol) commercially available clostin and nitrofurantoin discs (cl10 and F50) were used as control. All plates were incubated at $37^{\circ} \mathrm{C}$ for $18-24$ hours and the zones of inhibition (diameter in $\mathrm{mm}$ ) were measured on the agar surface.

\section{Data analysis}

Data were analyzed using Microsoft excel. Study findings were explained in words, table and figure.

\section{Ethical considerations}

The study obtained approval from the Head of Muhoza health center. This study also applied and was granted 
ethical clearance form INES-Ruhengeri research committee. Informed patient's consent form was sought and obtained through writing from participants. All patients' data gathered in this study were handled confidentially by the researcher. Furthermore, laboratory coding was used to identify patients from whom the data was obtained.

\section{RESULTS}

Bacterial identification among digestive tract infections Figure 1 below shows the percentage of bacterial isolates from stool samples of the patients suffering from digestive tract infections at Muhoza health center. Out of the 30 stool samples examined, Escherichia coli $(46.6 \%)$ was the most prevalent isolate followed by Salmonella species (33.33\%), Enterobacterspp (10.0\%), Shigellaspp (6.6\%) while Citrobacter $(3.33 \%)$ was the least encountered isolate.

Antimicrobial activity of ethanol oil extracted from ginger roots against bacterial pathogen isolated from digestive tract infections by using disc diffusion method

Figure 2 shows antibacterial activity of ginger oil extracts of ethanol on bacterial isolates on Mueller Hilton Agar. Among five species isolated from digestive tract, including E. coli, Salmonella spp, Shigella spp, Citrobacter and Enterobacter $s p$. Only Enterobacter spp showed the resistance to ginger ethanol extract. Moreover, Citrobacter spp was inhibited by the ginger at $(14 \mathrm{~mm})$ of zone of inhibition, followed by Shigella spp at $(12 \mathrm{~mm})$, Salmonella spp at $(11 \mathrm{~mm})$, and E.coli at $(9 \mathrm{~mm})$ of zone of inhibition.
Antimicrobial activity of methanol extract of ginger oil roots against bacterial pathogen isolated from digestive tract infections by using disc diffusion method

Susceptibility and resistance of isolated bacteria were shown using the extraction of ginger roots. Methanol was also used to extract ginger roots. The figure3 below indicates that maximum zone of inhibition $(12 \mathrm{~mm})$ against Citrobacter spp. Followed by Shigella spp. (11 mm), and E. coli (8mm), Salmonella spp $(6.1 \mathrm{~mm})$ and Enterobacter spp $(5 \mathrm{~mm})$.

\section{DISCUSSION}

Bacterial identification among digestive tract infections The present study was done to identify bacteria mostly found in digestive tract.Figure1 shows that Escherichia coli (46.6\%) Salmonella species (33.33\%), Enterobacter spp $(10.0 \%)$, Shigella spp (6.6\%) and Citrobacter spp (3.33\%) were detected from stool samples respectively. The findings imply that E. coli is the most prevalent and this is because E. coli is part of the normal gastrointestinal microflora which exerts a barrier effect Enterobacteriaceae. However, E. coli may be pathogenic when an individual ingestion of contaminated food or water, infected individual develops a watery diarrhea and abdominal cramps. Since the study considered only suffered from digestive tract infection, it should be taken that some pathogenic E. Coli was present even the study has not been able to detect them at time.

Similar results were reported from the study conducted by Kamrul et al determined the antimicrobial activity of soybean oil extract of dried ginger powder, using agar diffusion assay, against 24 isolates (4 of 6 different types)

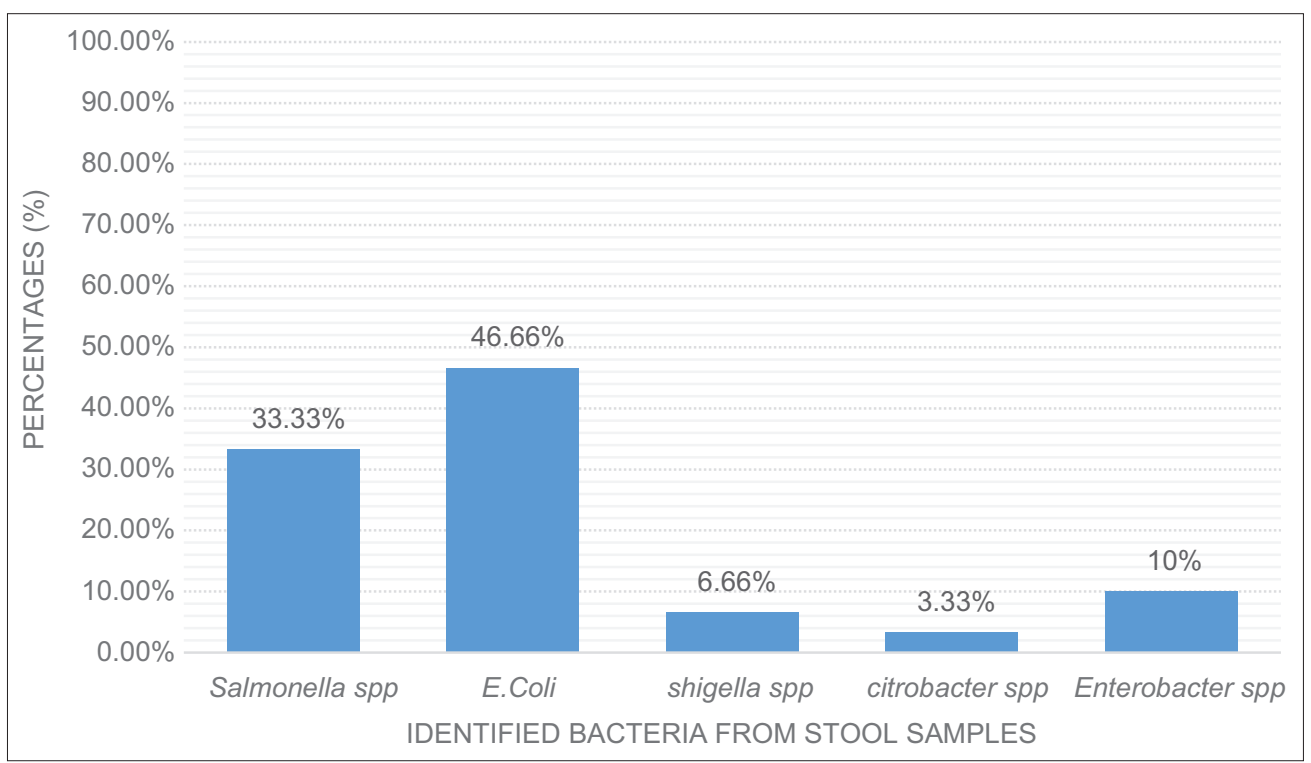

Figure 1: Bacteria identification isolated from digestive tract infections. 


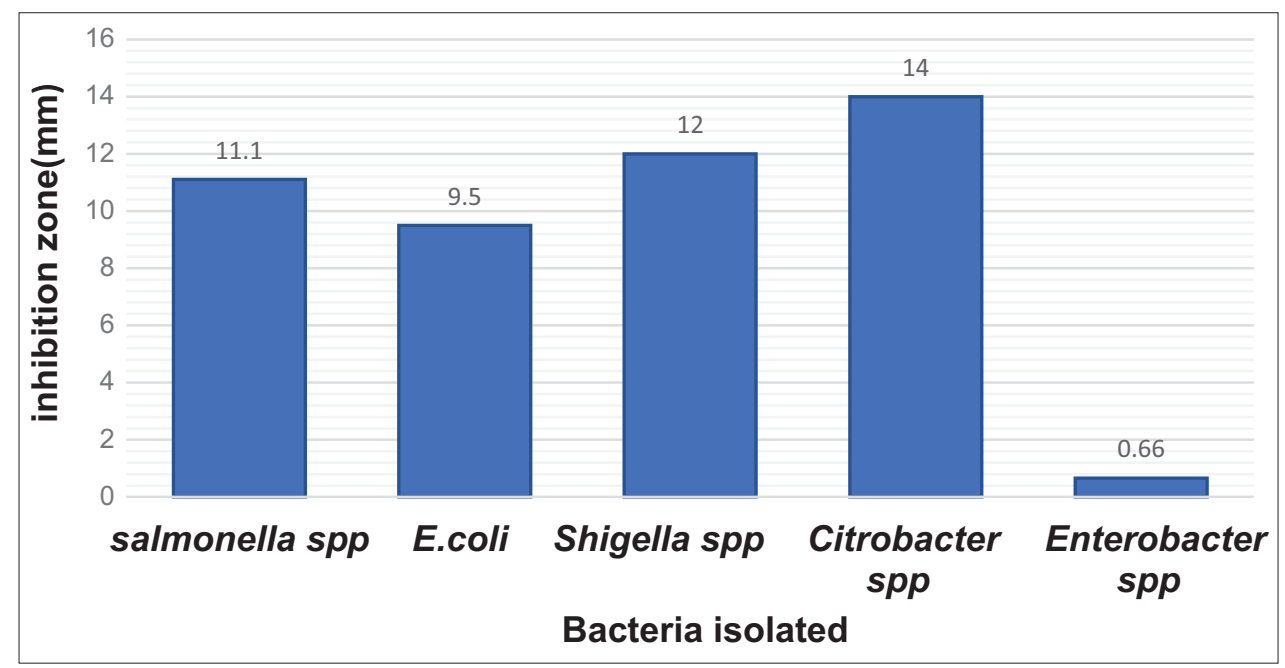

Figure 2: Isolated bacteria and their zone of inhibition of ethanol extract of Ginger plants.

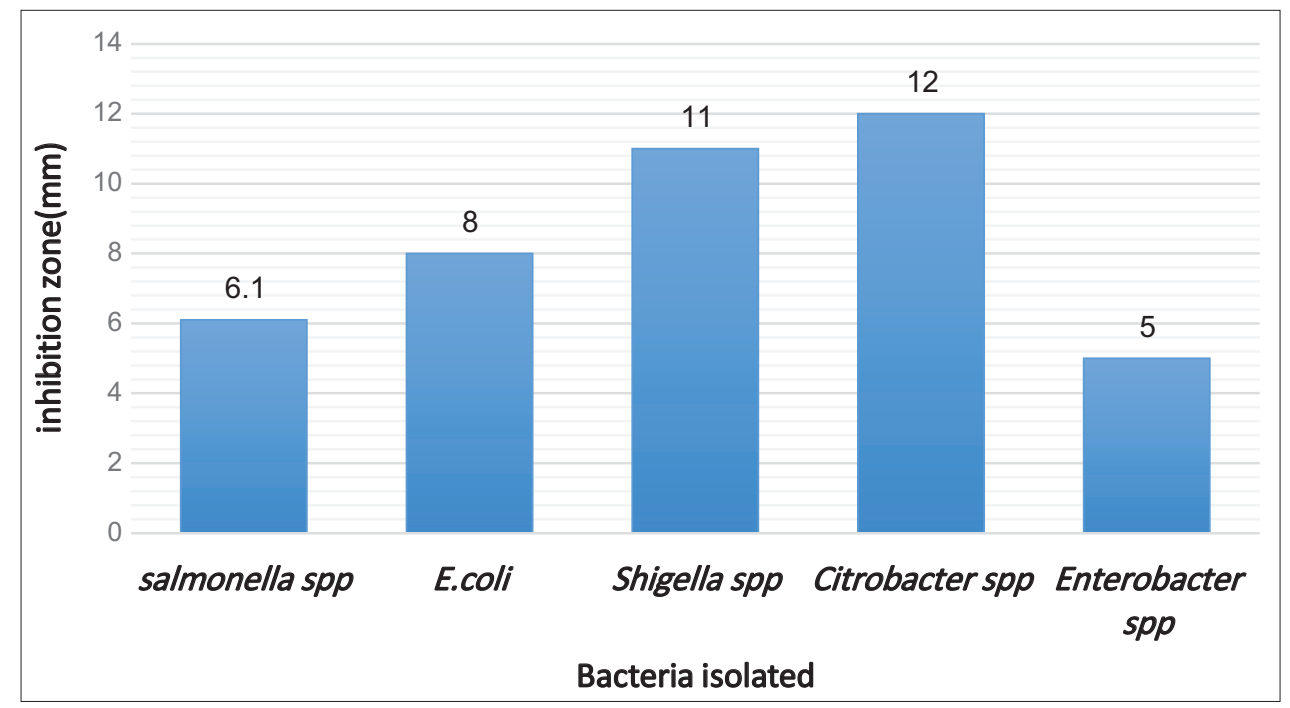

Figure 3: Isolated bacteria and their zone of inhibition of Methanol extract of Ginger plant.

of food borne pathogens including Escherichia coli, Pseudomonas aruginosa, Staphylococcus aureus, Klebsiella spp. and Salmonella spp. ${ }^{7}$ This shows some commonalities among study bacteria but different on other some species as both studies have not taken the same samples. Other study done by Okiki et al. showed that crude extract of the Ginger can inhibit the growth of oral bacteria in vitro. ${ }^{4}$

Other study conducted by Tong et al indicated that $\mathrm{S}$. aureus is the most predominant bacteria in selected food items followed by E. coli. ${ }^{9}$ It is known that E. coli and S. aureus are the most common pathogens found on hands and this can be an influence on their presence in food and they will later have a high prevalence in digestive tract path way. However, S. aureus was not isolated in the current study. According to Shaymaa et al the hands of the food handlers are the most important vehicle for the transfer of organisms from feces, nose and skin to the food. ${ }^{10}$ Other studies done by Trivedi et al indicated that the food samples were highly contaminated from the skin, mouth or nose of food handlers during handling, processing or vending because of poor food handling practices. ${ }^{11}$

Antimicrobial activity of ginger extracts against isolated bacteria

The present study was performed the antimicrobial activity of ginger extracts against isolated bacteria. The extractions of ginger were prepared by using methanol and ethanol. The present study showed the potential antimicrobial activity of the ginger extract against the all tested bacterial pathogens. Figure $2 \& 3$ indicates that maximum zone of inhibition $(14 \mathrm{~mm}$ and 12$)$ against Citrobacter spp. Followed by Shigella spp. $(12 \mathrm{~mm}$ and $11 \mathrm{~mm})$, and E.coli $(9.5 \mathrm{~mm}$ and $8 \mathrm{~mm})$, Salmonella spp $(11 \mathrm{~mm}$ and $6.1 \mathrm{~mm})$ and Enterobacter spp $(0.66 \mathrm{~mm}$ and $5 \mathrm{~mm}$ ), two inhibition zones are visible for each bacteria 
as two extracts were considered. Both extracts have been sensitive to Citrobacter but ethanol oil extracts have been high compared to methanol extracts and this was seen on other isolates like enterobacter where it shows a very low sensitivity for ethanol extracts but high to methanol. This shows how while extracting ginger, it should depend on which bacteria as they resist according to the type of extraction done. Ethanol extract has shown high antimicrobial activity compared to methanol extracts, the only one difference was shown on Entrobacter ssp where high sensitivity was seen in methanol extracts. However, ethanol could be good in extraction of ginger in case of digestive tract infection treatment.

The results were supported by Okikiet al carried out a study by Soybean oil extract of ginger showed highest zone of inhibition $(11.67 \pm 1.53 \mathrm{~mm})$ against Salmonella $s p p$. and lowest zone of inhibition $(8.0 \pm 1.73 \mathrm{~mm})$ against Escherichia coli. Ginger extract also showed lower zone of inhibition $(8.67 \pm 2.52 \mathrm{~mm})$ against Staphylococcus aureus compared to the Gram-negative bacteria. Soybean oil extract of ginger at boiling temperature has potential antimicrobial activity and could be used in food preparation to get the synergistic effect of soybean and ginger. ${ }^{4}$ Ginger has strong antibacterial and to some extent antifungal properties. In vitro studies have shown that active constituents of ginger inhibit multiplication of colon bacteria. These bacteria ferment undigested carbohydrates causing flatulence. This can be counteracted with ginger. It inhibits the growth of Escherichia coli, Proteus spp, Staphylococci, Streptococci and Salmonella spp. ${ }^{12}$

The analysis of the study does not enable us to determine main constituents of ginger while other studies done by Kamrul et al show the antibacterial activity and inhibition activity of ginger extracts could be attributed to the chemical properties of ginger. The main constituents of ginger are sesquiterpenoids with zingiberene as the main component. Other components include $\beta$-sesquiphellandrene, bisabolene and farnesene, which are sesquiterpenoids, and trace monoterpenoid fraction, ( $\beta$-sesquiphellandrene, cineol and citral). ${ }^{7}$ One question still unanswered in this study is that the ginger using was not measured by dose. However, the level of inhibition zone showed the level of antibacterial activity of Ginger oil extracts. Other studies done by Garvey et al showed that the results of the inhibition of bacterial growth have shown that the extracts are active at high concentration and inactive at very low concentrations. ${ }^{13}$ Thus the study may suggest that the inhibition of bacterial growth activity of the extracts is dose dependent.

\section{CONCLUSION}

In conclusion, the study showed different types of bacteria commonly found in digestive tract such as Escherichia coli $(46.6 \%)$ was the most prevalent isolate followed by Salmonella species (33.33\%), Enterobacter spp (10.0\%), Shigella spp (6.6\%) while Citrobacter (3.33\%) was the least encountered isolate. It also concluded that ginger extracts possess medicinal properties, antibacterial activity and that the inhibition of bacterial growth was dose dependent even though the study did not measure the dose of ginger extract used. Furthermore, ginger is considered to be a safe herbal medicine with only few and insignificant adverse or side effects.

\section{ACKNOWLEDGEMENT}

Gratitude thanks to Muhoza health center for facilitation in sample collection. We also thank INES Microbiology laboratory for the support of microbiological analysis.

\section{REFERENCES}

1. Seema R. Evaluation of synergistic effect of ginger, garlic, turmeric extraction on the antimicrobial activity of drugs against bacterial pathogens. International Journal of Biopharmaceutics 2015; 6 (2): 60-65.

2. Mostafa MS, Luluah MR, Samer AH and Alaa AO. Comparative Laboratory Study on Antimicrobial Effects of Fresh and Dry Ginger (Zingiberofficinale), Taif, KSA. Journal of Environmental Science, Toxicology and Food Technology 2014; 8 (9): 114-123.

3. Jalal B and Nasroallah MK. Physiological and pharmaceutical effects of Ginger (Zingiberofficinale Roscoe) as a valuable medicinal plant. European Journal of Experimental Biology 2014; 4 (1): 87-90.

4. Okiki PA, Oyetunji O and Oso B. Antibacterial activity of Ginger (Zingiberofficinale) against isolated bacteria from the respiratory tract infections. Journal of Biology Agriculture and Healthcare 2015; 5 (19): 131-138.

5. Riaz H, Begum AR, Khan Z, Yousaf $H$ and Tariq A. Antimicrobial property and phytochemical study of ginger found in local area of Punjab, Pakistan. International Current Pharmaceutical Journal 2015; 4 (7): 405-409.

6. Thomas $\mathrm{M}$ and Singh $\mathrm{S}$. Review article on Antimicrobial Resistance. Indian Journal of Research Pharmacy and Biotechnology 2013; 62 (1): 2320-3471.

7. Kamrul I, Asma AR, Murad K and Shahidul K. Antimicrobial activity of ginger (Zingiberofficinale) extracts against food borne pathogenic bacteria. International Journal of Science, Environment and Technology 2014; 3 (3): 867-871.

8. Regasa B. Aetiology of bacterial pathogens from adult patients with community-acquired pneumonia in Arba Minch Hospital, South Ethiopia. Science Journal of Clinical Medicine 2014; 3 (3): 33-36.

9. Tong SY, Davis JS, Eichenberger E, Holland TL and Fowler VG. Staphylococcus aureus infections: epidemiology, pathophysiology, clinical manifestations, and management. Clinical microbiology reviews 2015; 28 (3): 603-661.

10. Shaymaa KA, Rasha MS, Basam BM and Nabaa A. Antibacterial 
activity of Hibiscus rosa sinensis extract and synergistic effect with Amoxicillin against some human pathogens. American Journal of Phytomedicine and Clinical Therapeutics 2015; 3(1): 20-27.

11. Trivedi P, Sonali P and Seema B. Text book of microbiology. Mombai: Aavishkar Publishers, 2010.

12. Daihan S, Al-Faham M, Al-shawi N, Almayman RB, Zargar S and Shafi Bhat R. Antibacterial activity and phytochemical screening of some medicinal plants commonly used in Saudi Arabia against slected pathogenic microorganisms. Journal of King Saudi University of Sciences 2013; 25(1): 115-120.

13. Garvey MI, Rahman MM, Gibbons S and Piddock LJ. Medical plant extracts with efflux inhibitory activity against Gram negative bacteria. International Journal of Antimicrobial Agents 2011; 37(1): 145-151.

\section{Authors Contribution:}

CY- Research idea, data collection tool development and design, data and statistical analysis and discussion of results; AN- Data collection, sample collection and laboratory techniques application; SM- Data analysis; EM- Laboratory result analysis; JM- Review of Results and Laboratory Techniques.

Work attributed to:

Department of biomedical laboratory Sciences, faculty of applied fundamental sciences, INES-Ruhengeri-Institute of applied sciences.

\section{Orcid ID:}

Dr. Callixte Yadufashije - (D) https://orcid.org/0000-0002-3463-3725

Ms. Adolyne Niyonkuru - (D) https://orcid.org/0000-0002-1743-4847

Mr. Madjidi Sibomana - (D) https://orcid.org/0000-0002-8979-7364

Mr. Emmy Munyeshyaka - (1) https://orcid.org/0000-0001-9694-3676

Dr. Joseph Mucumbitsi- (1) https://orcid.org/0000-0002-9455-4981

Source of Support: Nil, Conflict of Interest: None declared. 